\title{
DIAGNOSTICS OF PLASMA PENCIL DISCHARGE FOR CHEMICAL ANALYSIS
}

\author{
P.SlaviceK ${ }^{a, *}$, A. Hrdicka ${ }^{b}$, M. Dvorakova ${ }^{b}$, V. KANICKY ${ }^{b}$ \\ a Department of Physical Electronics, Faculty of Science, Masaryk University, Kotlarska 267/2, 61137 Brno, \\ Czech Republic \\ ${ }^{b}$ Department of Chemistry, Faculty of Science, Masaryk University, Kotlarska 2, 61137, Brno, Czech Republic \\ * ps94@sci.muni.cz
}

\begin{abstract}
We present diagnostics of plasma pencil discharge as alternative excitation source for analytical chemistry. The plasma pencil is special type of rf plasma nozzle at atmospheric pressure. Through this nozzle flows working gas argon with aerosol. The aerosol sample introduction system employed a double pass Scott spray chamber with a pneumatic concentric nebulizer. The parameters of the plasma were calculated by optical emission spectroscopy.
\end{abstract}

Keywords: plasma pencil, atmospheric pressure plasma, OES, chemical analysis.

\section{Introduction}

Different plasma sources were used for chemical analysis. Inductively coupled plasma (ICP) and glow discharges [1] were used as very successful and versatile sources. Some alternatives, e.g. capacitively coupled plasma (CCP) $[2,3]$ or microwave-induced plasmas (MIPs) were studied for analytical purposes and various sub-types were constructed. A combination of a radio frequency (rf) plasma jet operating in the continuous mode and a laser-induced plasma was used for breakdown analysis of complex materials [4]. Plasma sources at low pressure were tested for chemical analysis too $[5,6]$.

Discharges at atmospheric pressure were used in most cases of measurements. Discharge sensitivity to water presence was limited stability and availability for chemical analysis. In case of ICP relatively high radio frequency (rf) power and high gas flow rates were used to maintain a big plasma, which is stable and resistant against water solutions.

Our study was aimed to rf plasma nozzle (plasma pencil) at atmospheric pressure as alternative excitation source for analytical chemistry. Plasma pencil had been a capacitively coupled plasma $(\mathrm{CCP})$ radio frequency jet discharge, operated typically in argon, at atmospheric pressure [7]. It had been originally designed and used for surface treatment of both recent and ancient objects. The convenience for special polymer film deposition has also been proven [8]. It has been further tested as an alternative excitation source for elemental analysis of liquids [9]. The analytical profit of this plasma source has been shown during the determination of $\mathrm{Li}, \mathrm{Na}, \mathrm{Mg}, \mathrm{Ca}, \mathrm{Cu}$ and $\mathrm{Zn}$ in aqueous solutions as representatives of alkali, alkali-earth and transition metals [9-11]. In this paper, we present diagnostics of rf plasma nozzle at atmospheric pressure. The parameters of the plasma source (rotational and excitation temperature) were calculated by optical emission spectroscopy [12] in the spectral range $200-750 \mathrm{~nm}$ for different parameters of rf discharge (power $140 \mathrm{~W}$ and $160 \mathrm{~W}$, working gas flow rate $4 \mathrm{slpm}$ and $5 \mathrm{slpm}$, position of detector).

Parameters (input rf power, working gas flow rate) were selected so that discharge was stable and resistant against water aerosol. Rotational and excitation temperature were measured along the discharge tube because strong dependence of intensity of emission lines on position was observed during experiments with aqueous solutions of alkali, alkali-earth and transition metals [9].

Advantage of tested discharge had been lower operational costs compared with conventional inductively coupled plasma or microwave induced plasma excitation sources for chemical analysis.

\section{Experimental}

The plasma was boosted by a Cesar 136 rf generator (Advanced Energy, China) at $13.56 \mathrm{MHz}$ frequency and the correct feedback was driven by a laboratory-made matching unit keeping the reflected power close to zero. The plasma was ignited with a spark coming from a hand Tesla transformer. The discharge is depicted in Fig. 1. It was enclosed in a $250 \mathrm{~mm}$ long quartz tube (i.d. $2 \mathrm{~mm}$ ) with a fused inlet of the same diameter under normal direction for aerosol introduction. The position $6.5 \mathrm{~cm}$ corresponds to the ground electrode and the power electrode is on position $0 \mathrm{~cm}$ (Fig. 1). The main argon stream was dosed with a mass flow controller. The aerosol sample introduction system employed a peristaltic pump and a double pass Scott spray chamber with a pneumatic concentric nebulizer. The created aerosol was transported by the carrier gas perpendicularly into the main discharge argon stream. The carrier argon entering the nebulizer was controlled with a mechanical rotameter $(0.3 \mathrm{slpm}-$ standard litre per minute). 


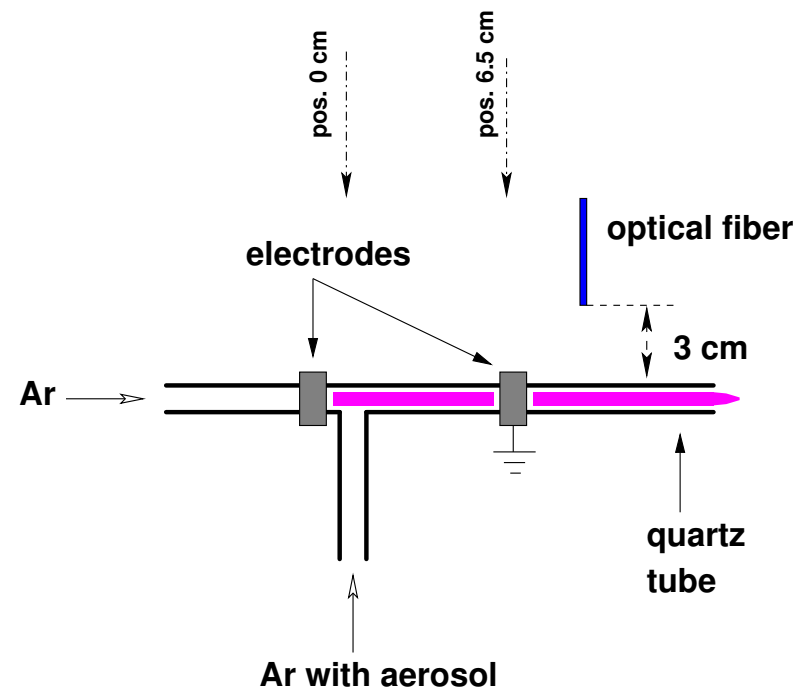

Figure 1. Experimental arrangement of the discharge.

Plasma radiation was collected with a quartz optical fibre, fitted to a movable holder on a scaled rail for exact positioning with respect to the discharge tube, and delivered to Andor Shamrock 750 spectrometer (grating 2400 grooves $\mathrm{mm}^{-1}$ ) equipped with iDus 416 CCD camera cooled by a Peltier cooler.

The rotational and excitation temperatures were calculated by optical emission spectroscopy for different input power of discharge, working gas flow rate and position along the discharge tube. These experiments were performed with and without aerosol. Pure deionised water was used for the experiment.

\section{Results and discussion}

Main task of our experiments was the optical emission diagnostics of the plasma. Rotational temperature from Boltzmann plots of rotational lines of $\mathrm{OH}$ spectra (Q1 branch in $0-0$ band, transition $\left.\mathrm{A}^{2} \Sigma \rightarrow \mathrm{X}^{2} \Pi\right)$ and excitation temperature from Boltzmann plots of Ar lines (603.21, 667.73, 675.28, 687.13, $714.70 \mathrm{~nm}$ ) were calculated for different parameters of rf discharge. Errors of rotational and excitation temperatures were calculated from linear regression of Boltzmann plots and were about $10 \%$. Identification of spectral lines and calculation of rotational and excitation temperatures were done using the Spectrum Analyzer software [13]. Rotational temperature can approximate temperature of heavy particles in discharge. Excitation temperature can approximate electron temperature. Temperature of plasma has a big impact on excitation and ionization of chemical elements.

Rotational temperatures from $\mathrm{OH}$ for different input power $(140 \mathrm{~W}, 160 \mathrm{~W})$ and different working gas flow rate $(4 \mathrm{slpm}, 5 \mathrm{slpm})$ without aerosol were measured first. Results of profiles along the discharge tube are depicted in Fig. 2. Errors of rotational temperature for input power $160 \mathrm{~W}$ and different working gas flow rate are presented in Fig. 3. The display of the error bars for all curves in Fig. 2 would be much cluttered. The

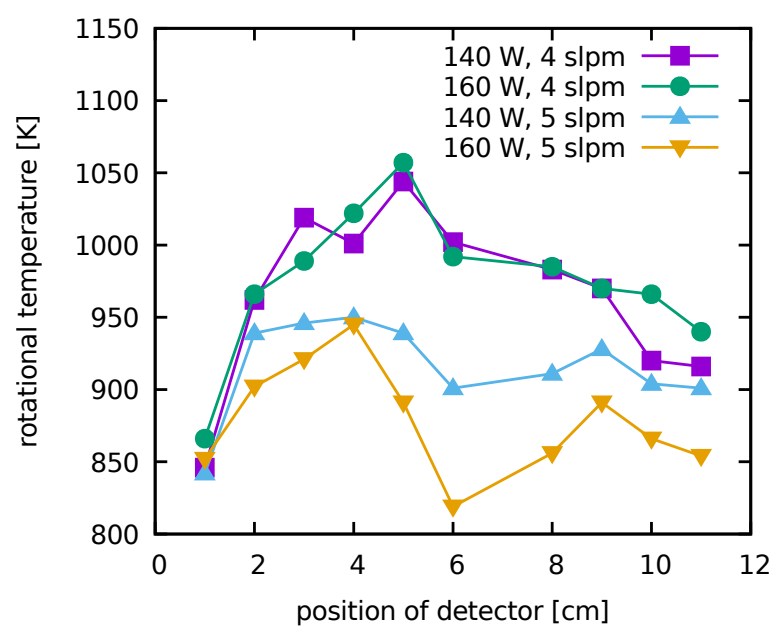

Figure 2. Rotational temperature profile along the discharge axis without aerosol for different power and working gas flow rate.

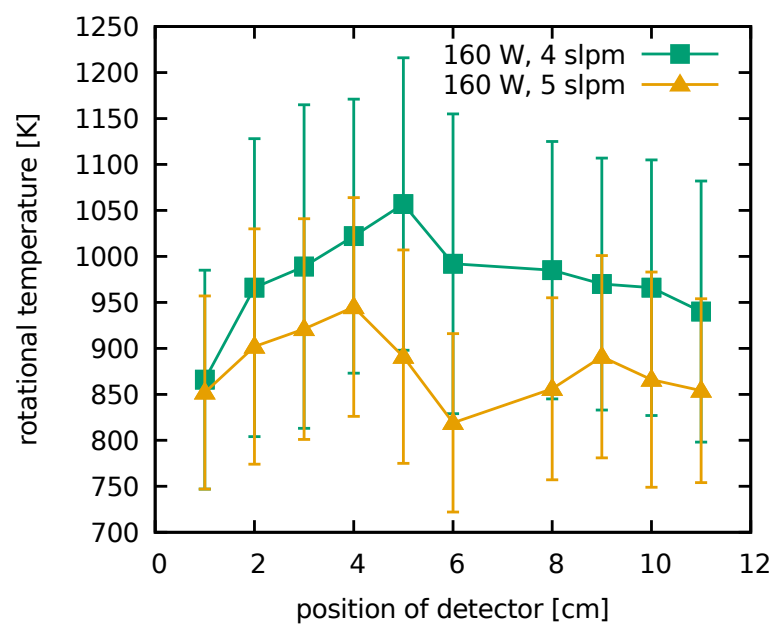

Figure 3. Rotational temperature profile along the discharge axis without aerosol for power $160 \mathrm{~W}$ and different working gas flow rate with error bars.

different shapes of temperature dependencies Fig. 2, Fig. 3 for higher working gas flow rate were caused by cooling effect of gas flow.

Next measurements were done with same parameters of input power and working gas flow rate with aerosol. Results are presented in Fig. 4. Comparison of rotational temperatures for input power $140 \mathrm{~W}$ and $160 \mathrm{~W}$ for same working gas flow rate $4 \mathrm{slpm}$ with and without aerosol is presented in Fig. 5. Rotational temperature has maximum at position about $5 \mathrm{~cm}$. Discharge with aerosol has higher temperature than discharge without aerosol (Fig. 5). The temperature of discharge without aerosol can be changed by argon flow rate (Fig. 2). The temperature of discharge with aerosol is practical independent on input rf power and argon flow rate (Fig. 4).

Excitation temperatures from Ar lines for different input power $(140 \mathrm{~W}, 160 \mathrm{~W})$ and different working gas flow rate $(4 \mathrm{slpm}, 5 \mathrm{slpm})$ without aerosol were 


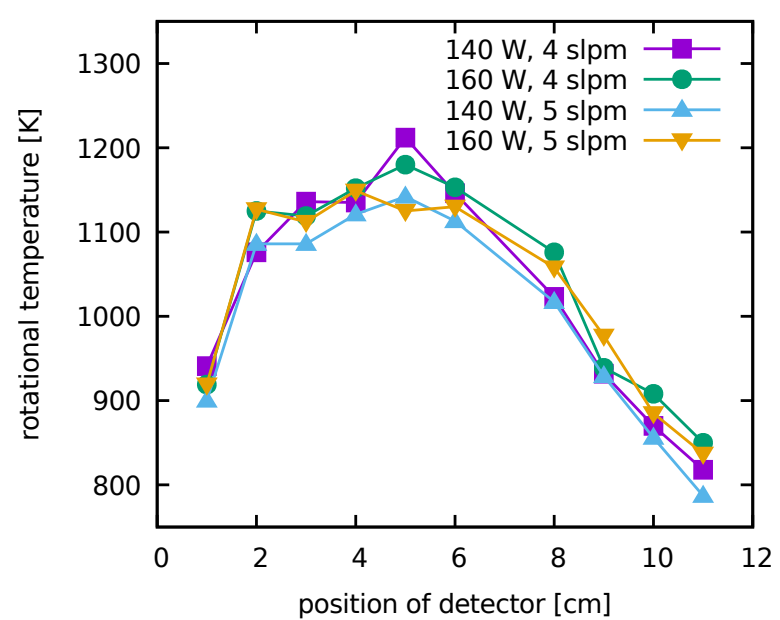

Figure 4. Rotational temperature profile along the discharge axis with aerosol for different power and working gas flow rate.

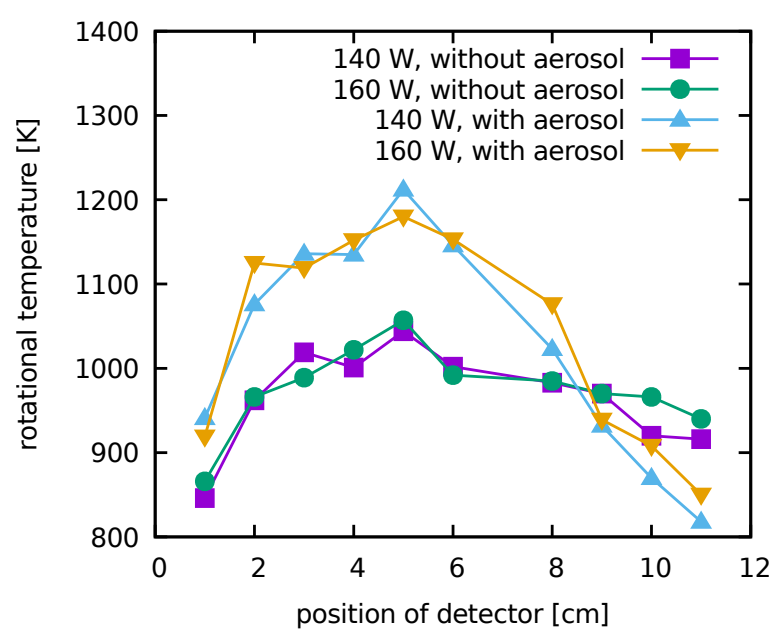

Figure 5. Rotational temperature profile along the discharge axis with and without aerosol for different power for same working gas flow rate (4 slpm).

measured. Results of profiles along the discharge tube are depicted in Fig. 6. Measurements were done with same parameters of input power and working gas flow rate with aerosol. Results are presented in Fig. 7. Comparison of excitation temperatures for input power $140 \mathrm{~W}$ and $160 \mathrm{~W}$ for same working gas flow rate $4 \mathrm{slpm}$ is presented in Fig. 8.

Excitation temperature has not maximum as rotational temperature. Discharge with water aerosol has lower excitation temperature than discharge without aerosol (Fig. 8). Decline of the temperature along the discharge tube is significant in case of discharge with aerosol.

Significant contraction of plasma along the discharge tube was observed in case with aerosol during all measurement.

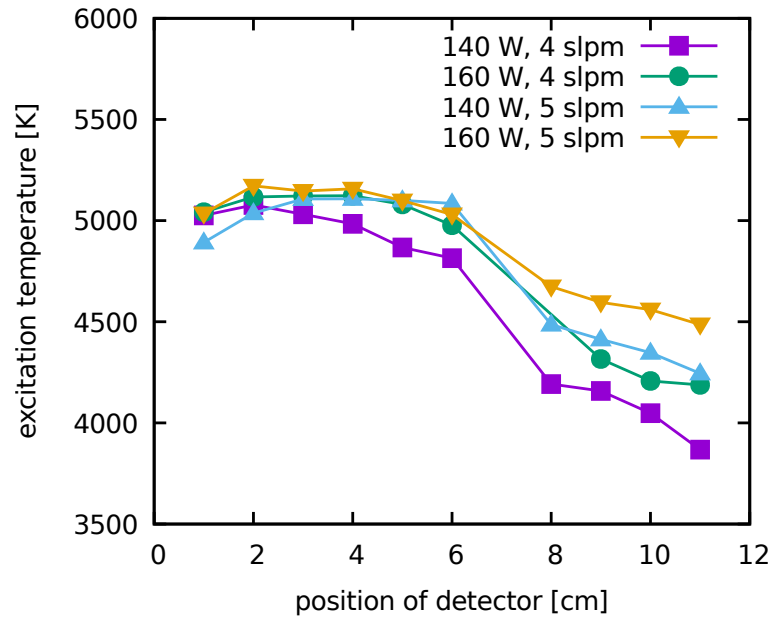

Figure 6. Excitation temperature profile from the argon lines without aerosol for different power and working gas flow rate.

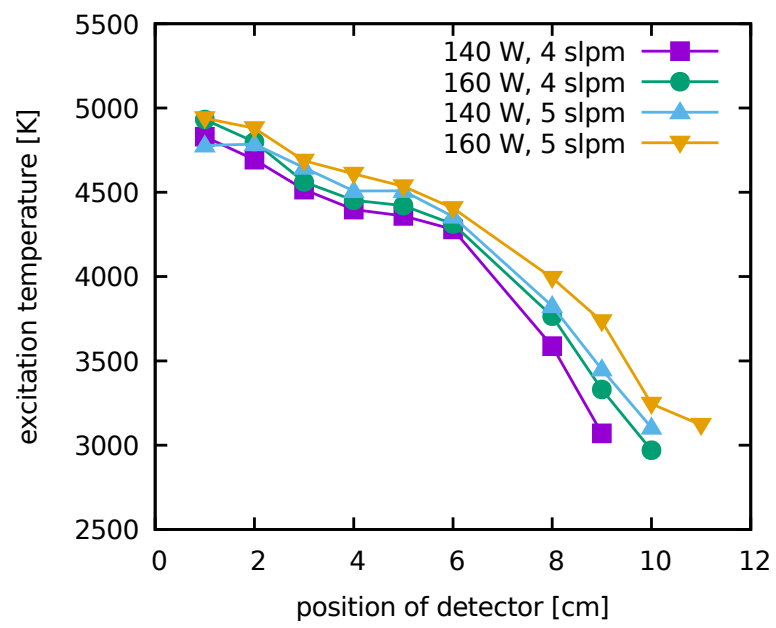

Figure 7. Excitation temperature profile from the argon lines with aerosol for different power and working gas flow rate.

\section{Conclusions}

The plasma nozzle at atmospheric pressure presented an alternative excitation source for analytical chemistry. Diagnostics by optical emission spectroscopy of this plasma nozzle were presented in this contribution. Rotational and excitation temperature of discharge were calculated for different parameters (input rf power, gas flow rate, position along discharge tube) with and without aerosol. Discharge with aerosol has higher rotational and lower excitation temperature then in case without aerosol. Discharge parameters have influence on application of this capacitively coupled plasma source for chemical analysis.

\section{Acknowledgements}

This research has been supported by the project CZ.1.05/2.1.00/03.0086 funded by European Regional Development Fund, by the project LO1411 (NPU I) funded by Ministry of Education Youth and Sports of Czech Republic 


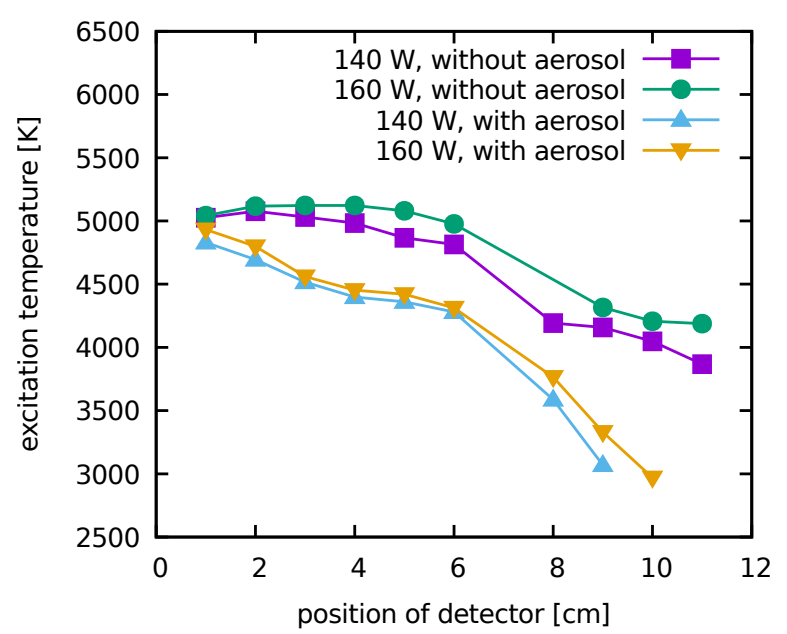

Figure 8. Excitation temperature profile from the argon lines with and without aerosol for different power for same working gas flow rate (4 slpm).

and by the project MUNI/A/1375/2018.

\section{References}

[1] N. Bings, A. Bogaerts, and J. Broekaert. Atomic spectroscopy. Analytical Chemistry, 80:4317-4347, 2008. doi:10.1021/ac8006297.

[2] T. Frentiu, M. Ponta, M. Senila, A. Mihaltan, E. Darvasi, and M. Frentiu. Evaluation of figures of merit for $\mathrm{zn}$ determination in environmental and biological samples using EDL excited AFS in a new radiofrequency capacitively coupled plasma. Journal of Analytical Atomic Spectrometry, 25:739-742, 2010. doi:10.1039/b918872j.

[3] R. Gross, B. Platzer, E. Leitner, A. Schalk, H. Sinabel, H. Zach, and G. Knapp. Atomic emission gas chromatographic detection chemical and spectral interferences in the stabilized capacitive plasma (SCP). Spectrochimica Acta Part B, 47:95-106, 1992. doi: 10.1016/0584-8547 (92)80010-E.

[4] J. Pedarnig, J. Heitz, E. Ionita, G. Dinescu, B. Praher, and R. Viskup. Combination of RF-plasma jet and laserinduced plasma for breakdown spectroscopy analysis of complex materials. Applied Surface Science, 257:54525455, 2011. doi:10.1016/j.apsusc. 2010.11.112.

[5] V. Mazakova, D. Trunec, and F. Krcma. Study of nitrogen flowing afterglow with mercury vapor injection. The Journal of Chemical Physics, 141:154307-1 154307-9, 2014. doi:10.1063/1.4898367.

[6] V. Mazakova, D. Trunec, Z. Navratil, J. Raud, and F. Krcma. Study of argon-oxygen flowing afterglow. Plasma Sources Science and Technology, 25:1-10, 2016. doi:10.1088/0963-0252/25/3/035008.

[7] J. Janca, M. Klima, P. Slavicek, and L. Zajickova. HF plasma pencil - new source for plasma surface processing. Surface and Coatings Technology, 116:547-551, 1999.

[8] P. Slavicek, V. Bursikova, A. Brablec, V. Kapicka, and M. Klima. Deposition of polymer films by rf discharge at atmospheric pressure. Czechoslovak Journal of Physics, 54(3 Supp):C586, 2004. doi:10.1007/BF03166455.
[9] L. Novosad, A. Hrdlicka, P. Slavicek, V. Otruba, and V. Kanicky. Plasma pencil as an excitation source for atomic emission spectrometry. Journal of Analytical Atomic Spectrometry, 27:0267-9477, 2012. doi:10.1039/c1ja10278h.

[10] L. Novosad, A. Hrdlicka, P. Slavicek, V. Otruba, and V. Kanicky. Possibilities and analytical properties of the radiofrequency plasma pencil operating in the continuous and in the pulsed mode. Journal of Analytical Atomic Spectrometry, 30:459-467, 2015. doi:10.1039/c4ja00402g.

[11] M. Dvorakova, A. Hrdlicka, P. Slavicek, V. Kanicky, and V. Otruba. Effects of easily ionisable elements on copper and zinc lines excited in a plasma pencil. Journal of Analytical Atomic Spectrometry, 31:2031-2036, 2016. doi:10.1039/c6ja00215c.

[12] R. Korneva, P. Sennikov, L. Shabarova, A. Shishkin, T. Drozdova, and S. Sintsov. Reduction of boron trichloride in atmospheric-pressure argon-hydrogen radiofrequency induction plasma. High Energy Chemistry, 53:246-253, 2019. doi:10.1134/S001814391903010X.

[13] Z. Navratil, D. Trunec, R. Smid, and L. Lazar. A software for optical emission spectroscopy - problem formulation and application to plasma diagnostics. Czechoslovak Journal of Physics, 56:B944-B951, 2006. doi:10.1007/s10582-006-0308-y. 